\title{
Flipped learning en educación médica, ¿de verdad los alumnos están preparados?
}

\section{Isabel Sánchez-Vera ${ }^{\mathrm{a}}$, Rima Barhoum ${ }^{\mathrm{b}}$, Esther Escudero ${ }^{\mathrm{b}}$ y Úrsula Muñoz}

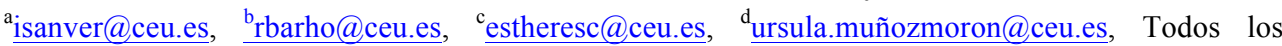
autores tienen la misma procedencia: Sección de Fisiología. Dpto. Ciencias Médicas Básicas. Facultad de Medicina. Universidad San Pablo CEU, Madrid.

\begin{abstract}
In recent years, the way of teaching has evolved with new technological advances and both teachers and students have been experimenting with new ways of teaching and learning. Parallel to these advances, new teaching methodologies have been included in the classrooms aimed at making students more involved in their learning, including the most recent flipped learning. With the aim of studying the degree of student satisfaction with a new teaching tool during the subject of Physiology I, satisfaction surveys have been carried out where students' opinions on the new teaching tool are analyzed (tutorial videos and exercises of resolution in class) compared to more traditional methodologies (blackboard and slides). The results suggest that a significant percentage of students prefer new methodologies over traditional ones, however, it is striking that there is still a percentage of students who still prefer traditional methods, such as blackboard. This study suggests that the new teaching tools that are developed in university classrooms can be useful and be used as complementary methods to existing ones, as long as they are efficient both for students and for teachers.
\end{abstract}

Keywords: Flipped learning, slides, blackboard, ICT, teaching tools, university.

\section{Resumen}

En los últimos años la forma de impartir docencia ha ido evolucionando con los nuevos avances tecnológicos en paralelo a estos avances, se han ido incluyendo en las aulas nuevas metodologías docentes encaminadas a hacer a los alumnos más participes de su aprendizaje, entre ellas y de las más recientes el flipped learning. Con el objetivo de estudiar el grado de satisfacción del alumno frente a una nueva herramienta docente durante la asignatura de Fisiología I, se ha llevado a cabo encuestas de satisfacción donde se analizan las opiniones de los alumnos sobre la nueva herramienta docente (vídeos tutoriales y ejercicios de resolución en clase) frente a las metodologías más tradicionales (pizarra y diapositivas). Los resultados apuntan a que un porcentaje significativo de alumnos prefieren las nuevas metodologías frente a las tradicionales, sin embargo, llama la atención que aún hay 
un porcentaje de alumnos que siguen prefiriendo los métodos tradicionales, como la pizarra. Este estudio apunta a que las nuevas herramientas docentes que se desarrollan en las aulas universitarias pueden ser útiles y utilizarse como métodos complementarios a los ya existentes, siempre y cuando sean eficientes tanto para los alumnos como para el profesorado.

Palabras clave: Flipped learning, diapositivas, pizarra, TICS, herramientas docentes, universidad.

\section{Introducción}

El sistema de enseñanza en la Universidad ha cambiado considerablemente en un plazo de tiempo relativamente corto. Si analizamos los últimos 20 años aproximadamente la forma de impartir docencia ha ido evolucionando con los nuevos avances tecnológicos y tanto profesores como alumnos han ido experimentando nuevas formas de enseñar y de aprender. Las clases tradicionales que se impartían fundamentalmente con explicaciones en la pizarra se transformaron y se empezaron a introducir otros métodos alternativos. Así, algunos profesores se apoyaron en los recursos tecnológicos que había entonces y comenzaron a proyectar en sus clases transparencias elaboradas a mano o en el mejor de los casos impresas con el ordenador, que luego dejaban en reprografía como material complementario para los alumnos. En un plazo corto de tiempo las transparencias empezaron a ser sustituidas por diapositivas en power point $y$ aunque al principio sólo los profesores más entusiastas las elaboraron, con el transcurso de los años prácticamente todos los profesores tuvieron que actualizarse y elaborar las diapositivas de su asignatura en este nuevo formato. Sin duda, la posibilidad de incluir imagenes escaneadas de libros en las diapositivas mejoraba considerablemente la forma de mostrar a los alumnos los conceptos que antiguamente se dibujaban en la pizarra. Además de las presentaciones en power point comenzaron a desarrollarse otros programas informáticos al alcance de todos con los que elaborar presentaciones de apoyo a la docencia, como prezi o potwoon, por nombrar algunas de las más utilizadas. Actualmente el desarrollo vertiginoso de las nuevas tecnologías propicia la inclusión de nuevos formatos y herramientas disponibles para utilizar en el aula. Las posibilidades con las que cuenta un profesor para impartir su clase a día de hoy son infinitas y se hace necesario desarrollar en los profesores una serie de habilidades tecnológicas, además de docentes, que antiguamente no eran necesarias.

La aplicación de los nuevos métodos de enseñanza se ha ido implantando de forma progresiva pero rápida y ha supuesto un esfuerzo enorme a aquellos profesores que 
se han ido adaptando, bien de forma voluntaria, bien porque no les ha quedado más remedio. Sin embargo, para los alumnos el cambio no ha sido tan drástico puesto que su papel en el aula sigue siendo el mismo: escuchar al profesor explicar (con presentaciones o sin ellas) mientras cogen apuntes.

En los últimos tiempos y en paralelo a las aplicaciones tecnológicas que se han ido incluyendo en las aulas, se han empezado a desarrollar nuevas metodologías docentes encaminadas a hacer a los alumnos más participes de su aprendizaje y acabar así con el papel pasivo del alumnado dentro del aula. A los métodos de enseñanza precedentes, como el aprendizaje activo o los métodos inductivos, funcionales o de indagación, se han incorporado otros más recientes como el flipped learning, metodología creada por los profesores de química de Jonathan Bergmann y Aaron Sams, de Woodland Park High School en Colorado (Estados Unidos) en el año 2007.

Esta nueva metodología docente presenta numerosas ventajas pedagógicas respecto al modelo de enseñanza tradicional. Entre ellas, el modelo inverso mejora los resultados del aprendizaje de los alumnos y la adquisición de competencias, así como fomenta un ambiente colaborativo entre profesores y alumnos (O'Flaherty y Phillips, 2015). La aplicación en clase del flipped learning requiere una elevada carga de trabajo para el profesor, especialmente en los primeros años en los que tiene que generar material para el estudio previo de los alumnos. Además, como hemos dicho, necesitará también desarrollar una serie de habilidades tanto pedagógicas como tecnológicas que no hace tan fácil su puesta en marcha (Prieto, 2017). A pesar de ello, cada vez más profesores se unen a la comunidad educativa que usa esta metodología en clase. Pero, ¿y que opinan los alumnos de este nuevo método de impartir la materia? ¿están dispuestos a asumir su nuevo rol en el aula y ser más participes de su aprendizaje?. En el presente estudio se analizan las valoraciones de los alumnos respecto a la implementación en el aula del flipped leaning.

\section{Objetivos}

El objetivo principal de este trabajo es analizar el grado de satisfacción de los alumnos con distintas metodologías docentes desarrolladas a lo largo de una misma asignatura. 


\section{Desarrollo de la innovación}

La experiencia docente se ha llevado a cabo en la asignatura Fisiología I, que se imparte en el primer semestre del $2^{\circ}$ curso del Grado en Medicina (www.uspceu.com). Dicha asignatura es de carácter obligatorio y consta de 7,5 créditos ECTS. La metodología se ha llevado a cabo de forma simultánea en dos grupos de clases teóricas, lo que supone un total de 83 alumnos matriculados.

A lo largo de la asignatura se han empleado distintas metodologías docentes, si bien en el mismo día sólo se empleaba una de ellas. Independientemente de la metodología empleada el profesor proporcionó a los alumnos todo el material docente que los alumnos iban a necesitar para preparar la asignatura.

Las formas de impartir la clase las denominaremos de la siguiente forma:

1) Metodología tradicional: explicación en pizarra sin soporte tecnológico de ningún tipo. A día de hoy no se suelen impartir las clases de esta forma, desde que empezaron a utilizarse las presentaciones en power point, al menos en nuestra Facultad.

2) Metodología semi-tradicional: explicación con diapositivas a modo de charla magistral. Esta metodología es a la que los alumnos están más acostumbrados ya que se desarrolla así en la mayoría de las asignaturas.

3) Metodología flipped learning: en la presentación de la asignatura el profesor explica la metodología que se va a llevar a cabo, con el fin de que los alumnos conozcan la nueva dinámica con la que se va a trabajar en algunos temas de la asignatura. La metodología se llevó a cabo de la siguiente manera:

Previo al inicio de cada Bloque el profesor proporciona a los alumnos el material docente que iban a necesitar para preparar la asignatura, y que incluye:

- Índice de contenidos: se trata de un índice donde se relacionan los puntos de cada tema incluidos en dicho Bloque.

- Objetivos de aprendizaje: se trata de un listado de todo lo que los alumnos tienen que haber aprendido después de haber estudiado cada tema.

- Guía de estudio: son todas las diapositivas y/o información con la que se va a explicar el Bloque. Incluye por tanto las diapositivas de todos los temas del Bloque. Este documento pdf se denomina guía de estudio ya que se pretende que les sirva de guía para estudiar, pero en ningún caso se les proporciona como apuntes para su estudio exclusivamente. 
- Vídeos tutoriales: el profesor proporciona a los alumnos los vídeos elaborados por el mismo mediante una tableta gráfica Wacom. Su duración aproximada es de 5 minutos y en ellos los alumnos pueden aprender conceptos específicos.

- Material adicional: incluye noticias actuales de la materia, papers científicos para su lectura voluntaria,...

Toda esta información se les sube a los alumnos al campus virtual al inicio del Bloque para que los alumnos puedan acudir a clase con el material aportado por el profesor. Lo habitual es que los alumnos vayan con las diapositivas impresas en papel, aunque cada vez es más frecuente que acudan con la información en sus ordenadores portátiles o tablets.

La dinámica de esta metodología consiste en los siguiente: el profesor les indica a los alumnos con varios días de antelación que se preparen en su casa ciertos temas. Para ello los alumnos disponen de los objetivos de aprendizaje, de la guía de estudio y sobre todo de los vídeos elaborados por el profesor. Una vez visualizado el vídeo se les hace un pequeño test de comprobación en la aplicación forms (de Microsoft office 365) para ver si han entendido la materia y las respuestas se envían automaticamente al profesor que puede comprobar quiénes han visualizado el vídeo y si lo han entendido. De esta forma, cuando los alumnos llegan al aula el profesor ya no tiene que explicar determinados conceptos o temas de la asignatura, sino que la mayor parte del tiempo los alumnos lo pasan haciendo ejercicios propuestos por el profesor para profundizar en los contenidos y resolver todas las dudas que se le hayan planteado o que surjan conforme se resuelven preguntas. Así, lo habitual es que los alumnos trabajen en clase, bien de forma individual o por parejas, y el profesor esté con ellos resolviendo dudas y ayudándoles.

Ejemplos de ejercicios propuestos en clase utilizados de forma habitual en neustra asignatura son (I. Sánchez-Vera, Congreso Inred 2018):

- Preguntas tipo test de elección múltiple: preguntas conceptuales para que los alumnos puedan discutir y razonar de forma que asienten los conocimientos previos que han visualizado en los vídeos.

- Casos prácticos: se les plantean situaciones o casos, reales o imaginarios, para razonar. En concreto, en nuestra asignatura les entregamos casos clínicos que, junto a las preguntas de elección múltiple anteriormente descritas, los alumnos puedan entender la aplicación práctica de lo que están estudiando y sean capaces de ver la trascendencia de los conceptos esenciales. 
- Imágenes para identificar y completar: en estas imágenes se han eliminado las leyendas y toda la información relativa a ella. Los alumnos deben completarlas con todo tipo de detalles, lo que les ayuda a fijarse en detalles que muchas veces son importantes pero que fuera del aula les pasa desapercibidos.

- Búsquedas en internet: la mayor parte de los alumnos están en clase con sus ordenadores portátiles o incluso con el móvil, desde donde tienen acceso a internet. Esto facilita las búsquedas en la web como parte de su proceso de aprendizaje. En ocasiones les proponemos que busquen algún concepto en concreto para entender otro, o para afianzar conceptos, para ver la aplicación práctica o simplemente para poder contestar una pregunta de elección múltiple donde alguna de las respuestas propuestas no se ha explicado en clase y por tanto desconocen.

- Realización de esquemas o dibujos explicativos: algunas veces se les propone que ellos mismos hagan un esquema de lo que se les acaba de explicar o incluso hagan un dibujo. En nuestra asignatura el estudio por imágenes es muy efectivo, por lo que con esta actividad lo que se pretende es que afiancen los conceptos al ser ellos mismos los que tienen que crear la imagen. Por ejemplo, un ejercicio propuesto es que vayan dibujando en cada una de las células que hay en la nefrona, los distintos transportadores que intervienen, para posteriomente discutir acerca del mecanismo de acción de los diuréticos.

\section{Análisis de la experiencia docente}

Para conocer el grado de satisfacción con las diferentes metodologías desarrolladas se elaboró una encuesta en la que los alumnos valoraron cada una de ellas. Las preguntas que contestaron fueron las siguientes:

\section{Respecto a las clases en las que se explica en la pizarra (sin proyección de diapositivas):}

a) No me gustan/me aburren porque se hace muy lenta la clase.

b) Me gustan porque el profesor explica más despacio y así me entero bien.

\section{Respecto a las explicaciones en clase sólo con diapositivas:}

a) No me gustan porque para eso ya tenemos las diapositivas y podemos estudiarlas en casa sin necesidad de ir a clase.

b) No me gustan porque el profesor habla más deprisa y no puedo coger apuntes. 
c) Me gustan porque puedo seguir bien la clase y se lo que tengo que estudiar.

\section{Respecto a los ejercicios realizados en clase:}

a) No cambiaría nada (me parece bien hacerlos en grupo y en clase).

b) Me parece bien hacerlos en grupo o individual pero preferiría hacerlos en casa.

c) Me parece bien hacerlos en clase pero preferiría hacerlos de forma individual.

d) No me aportan nada porque nos ponemos a hablar entre nosotros de otras cosas que no tienen nada que ver con la clase. Basicamente me parecen una pérdida de tiempo.

\section{Respecto a la visualización de los vídeos tutoriales:}

a) No los he visto.

b) Los he visto antes de la clases.

c) Los he visto pero después de las clases.

d) Los he visto antes y después de las clases.

\section{Respecto a la utilidad de los vídeos tutoriales:}

a) No les encuentro utilidad, para eso ya tenemos las diapositivas o los libros, que está todo más completo.

b) Los veo útiles sólo para antes de las clases, así ya se de que me van a hablar y eso nos permite hacer ejercicios en clase.

c) Los veo útiles sólo para después, para poder repasar las clase cuando estoy estudiando.

d) Los veo útiles para antes de las clases (y así hacemos ejercicios) y para repasar

\section{Respecto al formato de los vídeos:}

a) No cambiaría nada.

b) Me parecen demasiado largos.

c) Me parecen demasiado cortos.

d) No me gusta la música o no les pondría música.

e) Cambiaría todo.

\section{Respecto al contenido de los vídeos:}

a) Entiendo que en los vídeos se visualizan los conceptos clave y que son una ayuda para el estudio, sin olvidar que también tengo las diapositivas, los libros y la explicación del profesor. 
b) Entiendo que con que solamente me estudie los vídeos ya tengo suficiente para aprobar la asignatura.

\section{Por último, elija la opción que más le motive para la clase de Fisiología:}

a) Explicaciones en la pizarra sin proyectar las diapositivas (y sin vídeos ni ejercicios).

b) Explicaciones en la pizarra y proyección de dispositivas (y sin vídeos ni ejercicios).

c) Explicaciones (con pizarra y/o diapositivas), intercalado con la realización de ejercicios (sin vídeos).

d) Visualización previa a las clases de los vídeos, de modo que el profesor pueda acortar el tiempo de explicaciones, se hagan ejercicios en clase y se corrijan en clase (eso implica que los vídeos hay que visualizarlos antes para que de tiempo a todo).

\section{Resultados}

Tras la cuantificación de las encuestas de satisfacción desarrolladas en clase para la valoración de las diferentes metodologías llevadas a cabo en la asignatura de Fisiología I en el Grado de Medicina, los resultados obtenidos fueron los siguientes:

\section{Respecto a las clases en las que se explica en la pizarra (sin proyección de diapositivas):}

a) No me gustan/me aburren porque se hace muy lenta la clase.

b) Me gustan porque el profesor explica más despacio y así me entero bien.

Según la figura 1 , se observa que un $72 \%$ de los alumnos consideran que la pizarra es una herramienta útil y necesaria para la comprensión de los conceptos más importantes en clase, incluso sin necesidad de apoyo con las diapositivas de power point, una de las herramientas más demandadas en todas las aulas de docencia. Por el contrario un $28 \%$ de los alumnos prefieren otras metodologías en clase antes que el uso de la pizarra.

Es llamativo como un alto porcentaje acepta la pizarra, la herramienta más antigua de la historia educativa como único instrumento de aprendizaje, sin ayuda y sin complemento de las tan ansiadas diapositivas proyectadas en pantalla. Este punto es digno de ser destacado en la actual era de la tecnología y en donde los métodos de innovación docente cada vez son más solicitados, esperados, incluso exigidos por las instituciones educativas. 


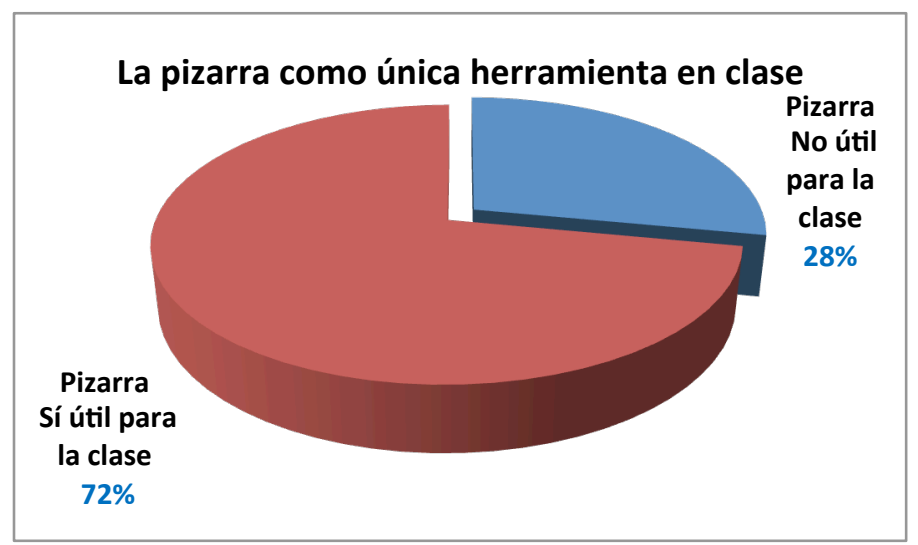

Figura 1: Resultados obtenidos tras realización de encuestra de satisfacción a los alumnos respondiendo a la siguiente pregunta: Respecto a las clases en las que se explica en la pizarra (sin proyección de diapositivas)

\section{Respecto a las explicaciones en clase con diapositivas:}

a) No me gustan porque para eso ya tenemos las diapositivas y podemos estudiarlas en casa sin necesidad de ir a clase.

b) No me gustan porque el profesor habla más deprisa y no puedo coger apuntes.

c) Me gustan porque puedo seguir bien la clase y se lo que tengo que estudiar.

Según la figura 2, un $66,7 \%$ de los alumnos encuestados opinan que en general las diapositivas en clase pueden ser una herramienta útil para el aprendizaje y comprensión del contenido de las unidades didácticas en Fisiología porque les permite seguir la clase y porque en ellas quedan reflejadas los conceptos más importantes para estudiar de cara al examen, es decir, se muestra una selección de contenidos que orienta al alumno sobre lo más importante dentro del tema que se está impartiendo. Por el contrario un 33,3\% de los alumnos dicen no gustarles esta herramienta ya que $20,6 \%$ no les gusta que sea herramienta de docencia en el aula porque las podrían utilizar por su cuenta en casa sin necesidad de acudir a clase, y un $12,7 \%$ justifica el hecho de que no acepten las diapositivas como herramienta del aula porque hace que el docente pueda explicar a una velocidad alta por lo que que les impediría a los alumnos tomar apuntes normalmente. 


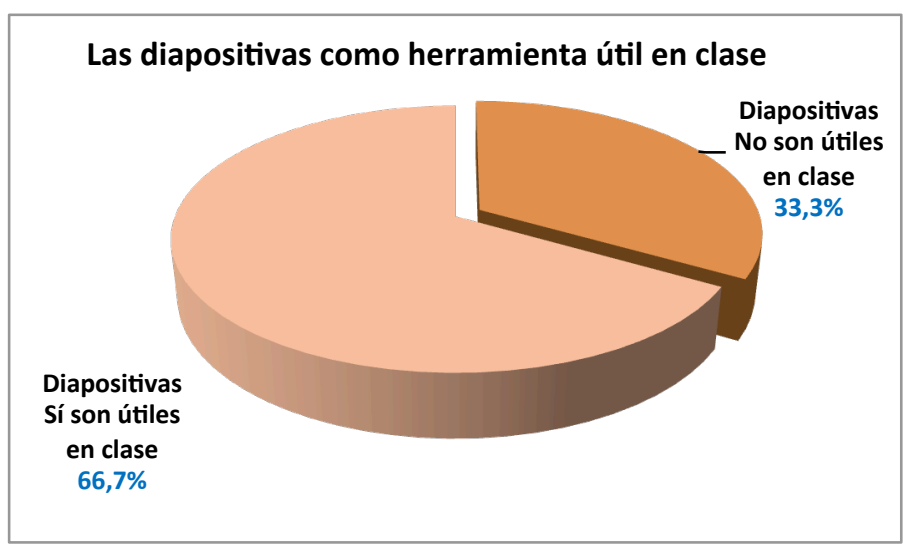

Figura 2: Resultados obtenidos tras realización de encuestra de satisfacción a los alumnos respondiendo a la siguiente pregunta: Respecto a las explicaciones en clase con diapositivas.

Es llamativo como aún existe un pequeño porcentaje de alumnos que consideran las diapositivas herramientas poco rentables en el aula, ya sea bien porque su lectura se podría hacer fuera del aula o ya sea porque al profesor le permite ir más deprisa, lo que les impediría tomar apuntes normalmente. Fue la proyección de las diapositivas una de las primeras herramientas que se aplicaron en el aula durante el inicio de la era de la tecnología. Esta herramiento nació con el objetivo de ser un apoyo gráfico para el profesor (Mesía, 2010) permitiéndole utilizar como índice para el seguimiento del contenido de la clase así como la proyección de gráficas e imágenes muy necesarias especialmente en esta asignatura de Fisiología Humana. Pero sucede que no siempre se hace esto de la manera más conveniente, porque, obviamente, para ser eficaces las diapositivas presentadas deben estar, en primer lugar, bien hechas y, en segunda instancia, correctamente empleadas. No obstante, se puede ver que muy a menudo sucede, por ejemplo, que el profesor cae en el grave inconveniente de limitarse a leer la presentación, como si se tratase de un papel en el que ha pegado todo lo que tiene que decir (Mesía, 2010). Sin embargo con el tiempo y de forma insidiosa sufrió una transformación en su finalidad, convirtiéndose en una herramienta muy solicitada por el alumno como guión base para sus apuntes y tal vez con el incoveniente de ahorrarse la consulta con el libro de texto.

\section{Respecto a los ejercicios realizados en clase:}

a) No cambiaría nada (me parece bien hacerlos en grupo y en clase).

b) Me parece bien hacerlos en grupo o individual pero preferiría hacerlos en casa.

c) Me parece bien hacerlos en clase pero preferiria hacerlos de forma individual. 
d) No me aportan nada porque nos ponemos a hablar entre nosotros de otras cosas que no tienen nada que ver con la clase. Basicamente me parecen una pérdida de tiempo.

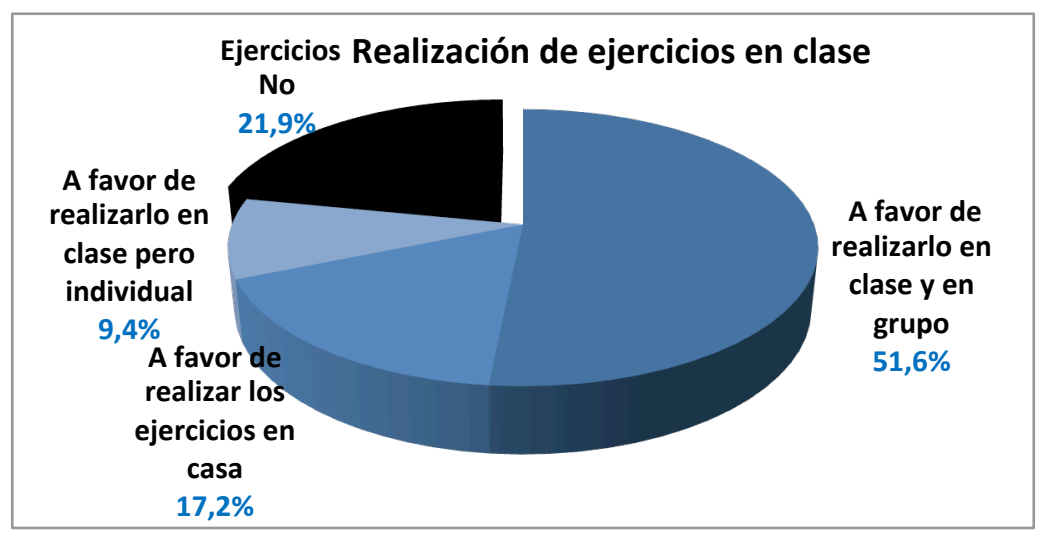

Figura 3: Resultados obtenidos tras realización de encuestra de satisfacción a los alumnos respondiendo a la siguiente pregunta: Respecto a los ejercicios realizados en clase.

Según los datos obtenidos, figura 3, un total de 78,2\% están a favor de la realización de ejercicios duante la hora de clase, un 51,6\% les gustaría que se realizara en grupo, un 9,4\% de forma individual y por último, un llamativo 17,2 \% prefieren hacerlos en casa, fuera del aula. Por contra un $21,9 \%$ no está muy por la labor de realizarlos argumentado que incitaría a conversar con los compañeros de otros temas ajenos al contenido de la clase, con lo que les haría perder el tiempo.

\section{Respecto a la visualización de los vídeos tutoriales:}

a) No los he visto.

b) Los he visto antes de la clases (cuando asi me lo han pedido).

c) Los he visto pero después de las clases.

d) Los he visto antes y después de las clases. 
Flipped learning en educación médica, ¿de verdad los alumnos están preparados?.

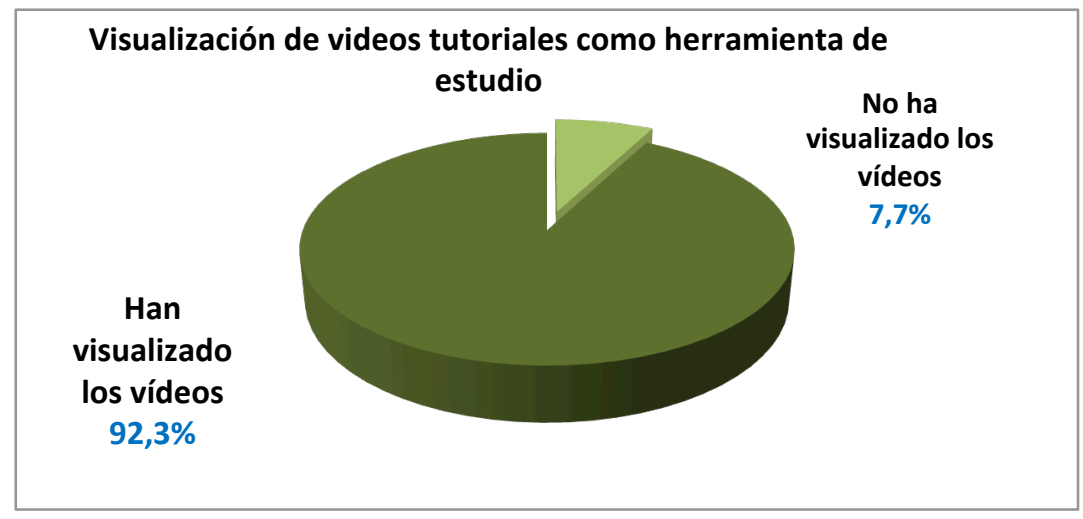

Figura 4: Resultados obtenidos tras realización de encuestra de satisfacción a los alumnos respondiendo a la siguiente pregunta: Respecto a la visualización de vídeos tutoriales relacionados con el tema a impartir en clase.

Según los datos obtenidos, se puede observar en la figura 4, como un 92,3\% de los alumnos indicaron que visualizaron los vídeos frente a un $7,7 \%$ que no utilizaron como herramienta de estudio y preparación de las clases.

Con respecto al $92,3 \%$ que han visualizado los videos, un $32,8 \%$ lo hicieron después de que impartieran su contenido en clase, un 30,8\% lo visualizaron antes de la clase, que es lo que indicó el profesor y un $29,2 \%$ antes y después de clase, figura 5 .

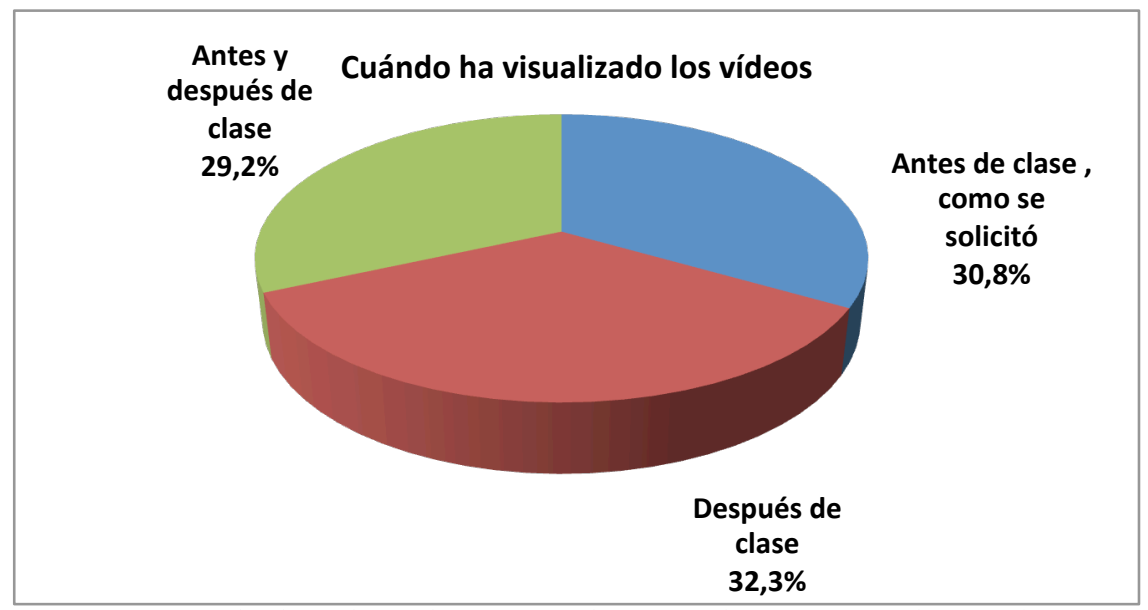

Figura 5: Resultados obtenidos tras realización de encuestra de satisfacción a los alumnos respondiendo a la siguiente pregunta: Respecto cuándo ha visualizado los vídeos tutoriales.

\section{Respecto a la utilidad de los vídeos tutoriales:}

a) No les encuentro utilidad, para eso ya tenemos las diapositivas o los libros, que está todo más completo.

b) Los veo útiles sólo para antes de las clases, así ya se de que me van a hablar y eso nos permite hacer ejercicios en clase. 
c) Los veo útiles sólo para después, para poder repasar las clase cuando estoy estudiando.

d) Los veo útiles para antes de las clases (y así hacemos ejercicios) y para repasar

Se representará sólo los alumnos que han visualizado los videos, quedando como anteriormente se ha descrito un $7,7 \%$ de alumnos que no han visualizado los videos y por lo tanto no les resulta útiles como herramienta de estudio. Según los datos que se observan en la figura 6 , como un $92,4 \%$ de los alumnos indicaron que los vídeos son útiles como herramienta de estudio. De las posibles respuestas recogidas en las encuestas, señalamos que un 45,5\% lo visualizaron dos veces, una antes de la clase y luego como repaso, un 33,3\% lo visualizaron sólo después de clase, y un $13,6 \%$ antes de clase, que realmente ese era el objetivo establecido por el profesor.

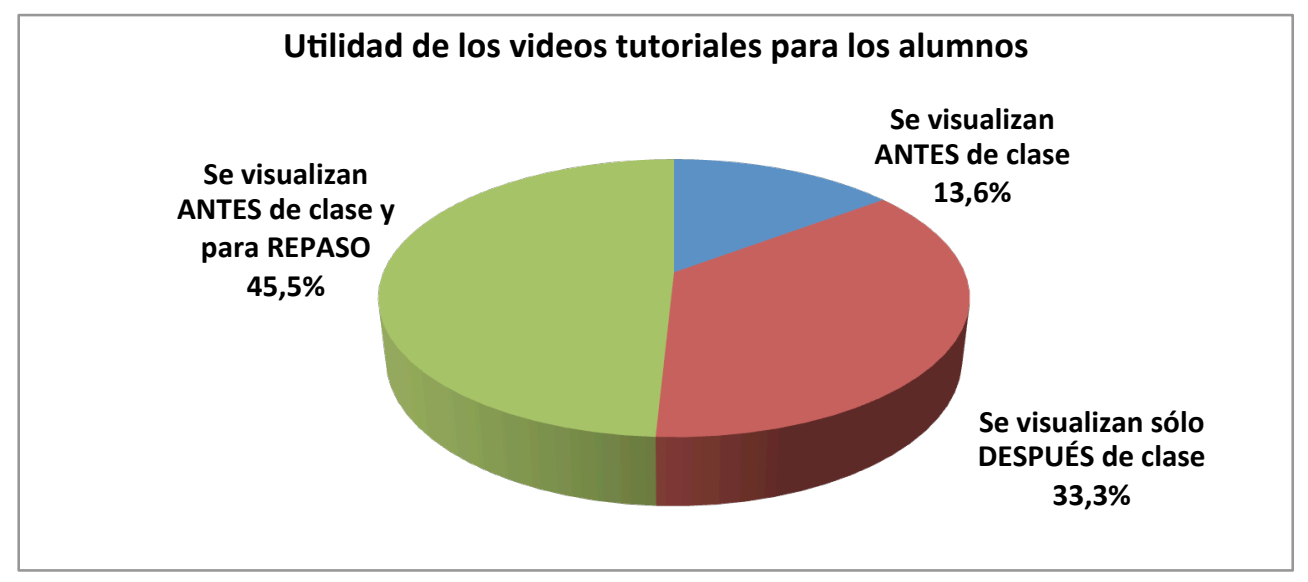

Figura 6: Respecto a la utilidad de vídeos tutoriales relacionados con el tema a impartir en clase hay una variedad de usos realizado por los alumnos

\section{Respecto al formato de los vídeos:}

a) No cambiaría nada.

b) Me parecen demasiado largos.

c) Me parecen demasiado cortos.

d) No me gusta la música o no les pondría música.

e) Cambiaría todo.

Como se observa en la figura 7, el formato de los vídeos tutoriales ha sido bastante bien aceptado por un $77,8 \%$ de los alumnos, frente a un $22,2 \%$ que cambiarían ciertos detalles como la duración del vídeo $(6,4 \%)$ y otro $7,9 \%$ que cambiarian por completo el formato. 


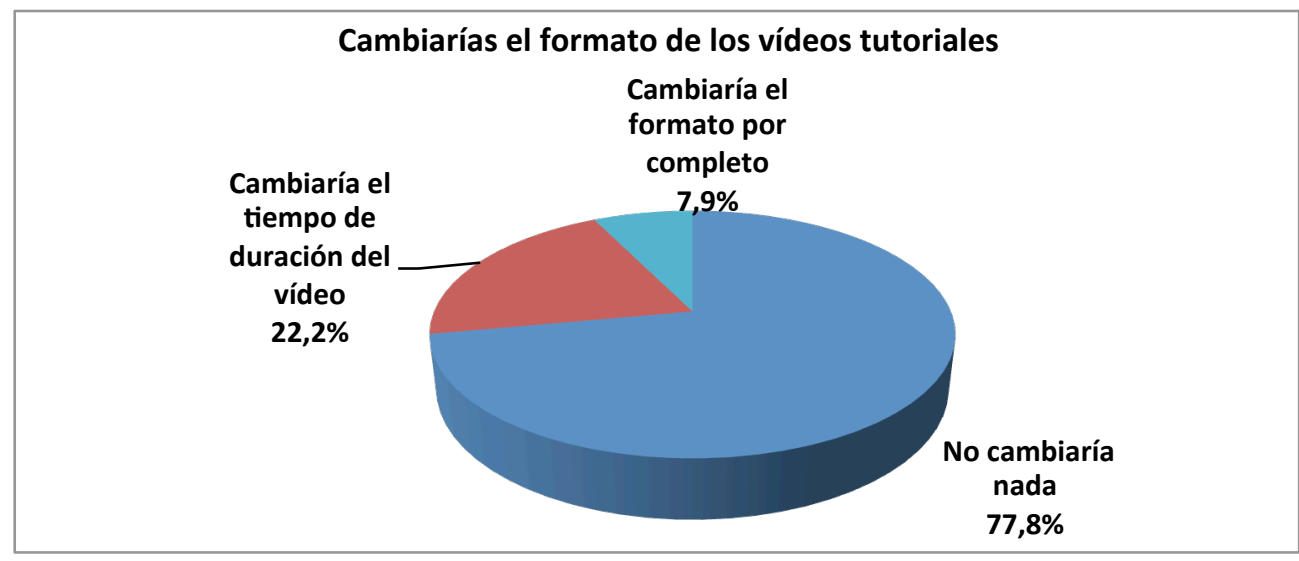

Figura 7: Datos de satisfacción de los alumnos opinando sobre el formato de los vídeos

\section{Respecto al contenido de los vídeos:}

a) Entiendo que en los vídeos se visualizan los conceptos clave y que son una ayuda para el estudio, sin olvidar que también tengo las diapositivas, los libros y la explicación del profesor.

b) Entiendo que con que solamente me estudie los videos ya tengo suficiente para aprobar la asignatura.

Como se observa en la figura 8 un $92,2 \%$ indicaron que es una herramienta muy útil complementaria a otros métodos de estudio frente a un $7,8 \%$ que indicaron que podría ser una herramienta única y suficiente para el estudio del contenido del tema.

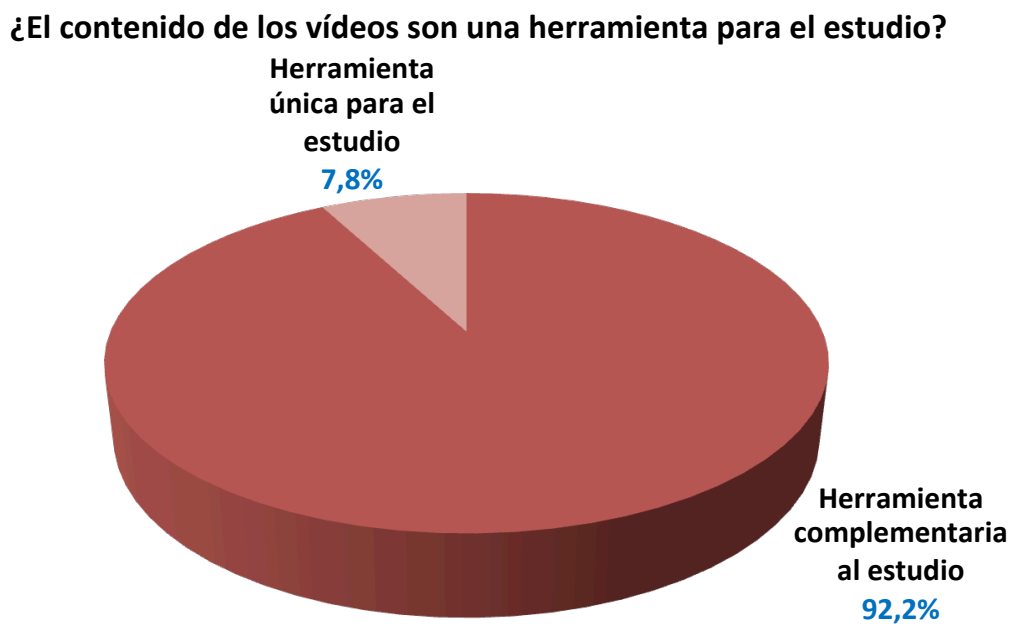

Figura 8: Respuestas de los alumnos a la pregunta sobre si los vídeos tutoriales pueden constituir una herramienta única o complementaria al estudio. 


\section{Por último, elija la opción que más le motive para la clase de Fisiología:}

a) Explicaciones en la pizarra sin proyectar las diapositivas (y sin vídeos ni ejercicios).

b) Explicaciones en la pizarra y proyección de dispositivas (y sin vídeos ni ejercicios).

c) Explicaciones (con pizarra y/o diapositivas), intercalado con la realización de ejercicios (sin videos).

d) Visualización previa a las clases de los vídeos, de modo que el profesor pueda acortar el tiempo de explicaciones, se hagan ejercicios en clase y se corrijan en clase (eso implica que los vídeos hay que visualizarlos antes para que de tiempo a todo).

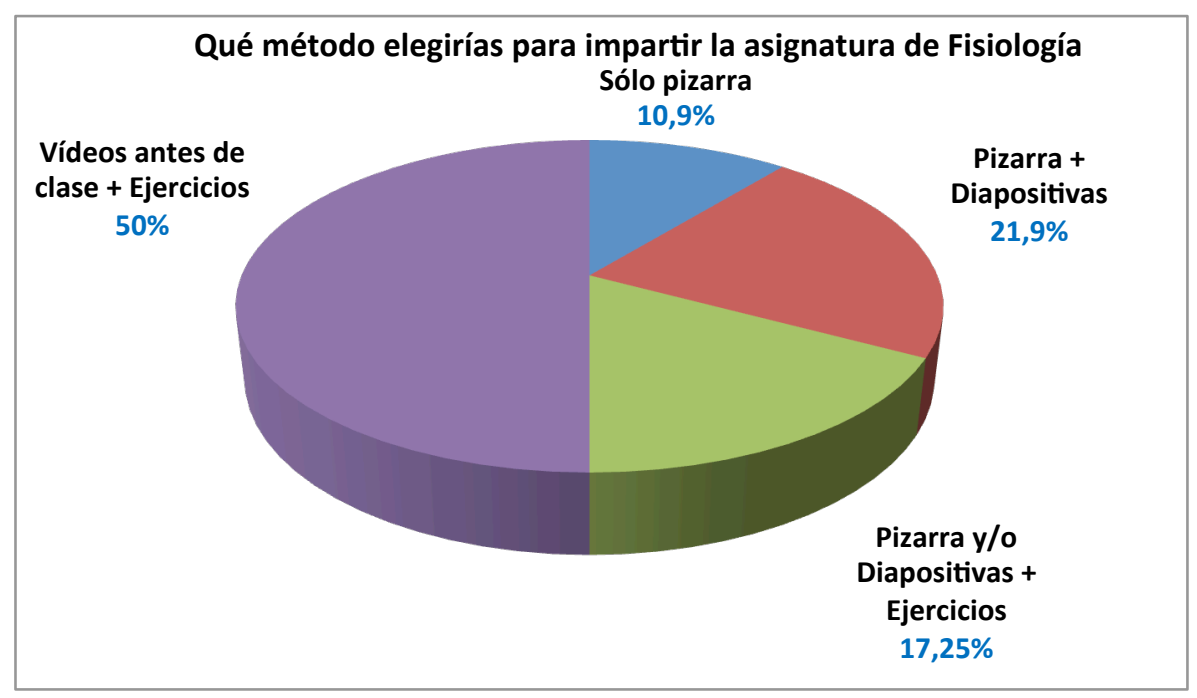

Figura 9: Representa las diferentes opiniones de los alumnos frente a la metodología que preferirían recibir durante la impartición de la asignatura de Fisiología I.

Según se observa en la figura 9, es la visualización de los vídeos previa a las clases para poder realizar ejercicios y poder corregirlos en clase la opción más elegida por el $50 \%$ de los alumnos. Un $21,9 \%$ prefieren explicaciones en la pizarra y proyección de dispositivas (sin vídeos ni ejercicios). Un $17,25 \%$ eligen explicaciones (con pizarra y/o diapositivas), intercalado con la realización de ejercicios (sin vídeos). Y un 10,9\% explicaciones en la pizarra sin proyectar las diapositivas (sin vídeos ni ejercicios). 


\section{Conclusiones}

En este trabajo se ha descrito y analizado la incorporación de distintas metodologías docentes a lo largo del desarrollo de una asignatura, focalizándonos en la opinión de los alumnos sobre cada una de ellas y sus preferencias a la hora de aprender.

Los resultados de la encuesta de satisfacción que completaron los alumnos reflejan que si bien hay alumnos dispuestos a implicarse en su aprendizaje y a asumir su responsabilidad en su enseñanza, todavía existe un número importante de alumnos que prefieren metodologías más tradicionales a las que ya están acostumbrados antes que la incorporación de otros métodos más novedosos como es el flipped learning.

Las resultados de este trabajo nos llevan a pensar que el cambio hacia una nueva metodología docente más activa por parte del alumno tiene que hacerse de forma progresiva puesto que todavía hay alumnos que no están preparados para asumir la responsabilidad de su aprendizaje.

\section{Referencias}

ARCÍA-VALCÁRCEL MUÑOZ-REPISO, Ana. Herramientas tecnológicas para mejorar la docencia universitaria. una reflexión desde la experiencia y la investigación. RIED. Revista Iberoamericana de Educación a Distancia, [S.1.], v. 10, n. 2, p. 125-148, dic. 2007. ISSN 1390-3306

BERGMANN, J., SAMS A. (2015). Dale la vuelta a tu clase: Lleva tu clase a cada estudiante, en cualquier momento y cualquier lugar. Biblioteca Innovación educativa. Editorial SM.

O'FLAHERTY, J., PHILLIPS, C. (2015). The use of flipped classrooms in higher education: A scoping review en Internet and Higher Education 25 85-95.

PRIETO, A. (2017). Flipped learning. Aplicar el modelo de apredizaje inverso. Editorial Narcea.

MESÍA MARAVI, R; El empleo didáctico de las diapositivas en power point Invest. Educ. 14 (26), 2010 